\title{
Cannabinoid Modulation of Opiate Reinforcement through the Ventral Striatopallidal Pathway
}

\author{
Stéphanie Caillé' and Loren H Parsons*, I \\ 'Department of Neuropharmacology, The Scripps Research Institute, La Jolla, CA, USA
}

\begin{abstract}
Recent evidence indicates that cannabinoid-I $\left(C B_{1}\right)$ receptors play a role in the mediation of opiate reward, though the neural mechanisms for this process have not been characterized. The present experiments investigated the influence of $C B_{1}$ receptors in the ventral striatopallidal system on opiate-induced neurochemical events and opiate self-administration behavior in rats. Acute morphine administration $(3 \mathrm{mg} / \mathrm{kg}$ ) significantly reduced ventral pallidal GABA efflux in a manner similar to that produced by heroin selfadministration. This neurochemical effect was reversed by doses of the selective CB, antagonist SR I4I7I6A (Rimonabant; I and $3 \mathrm{mg} / \mathrm{kg}$ ) that also significantly reduce opiate reward. Morphine-induced increases in nucleus accumbens dopamine levels were unaltered by SR 141716A. Intravenous heroin self-administration $(0.02 \mathrm{mg} /$ infusion) was significantly reduced by intra-accumbens, but not intraventral pallidal SR I4I7I6A infusions (I and $3 \mu \mathrm{g} / \mathrm{side}$ ), implicating nucleus accumbens $\mathrm{CB}_{\text {I }}$ receptors in the modulation of opiate reinforcement. In contrast, SRI47I6A did not alter cocaine self-administration ( $0.125 \mathrm{mg} / \mathrm{inf})$, cocaine-induced $(10 \mathrm{mg} / \mathrm{kg})$ decrements in ventral pallidal GABA efflux or cocaine-induced increases in accumbens dopamine. This is consistent with evidence that selective inactivation of $\mathrm{CB}_{1}$ receptors reduces opiate-, but not psychostimulant-maintained self-administration. The $\mathrm{CB}_{1}$ receptor agonist WIN $55,212-2(5 \mathrm{mg} / \mathrm{kg})$ reduced pallidal GABA efflux in a manner similar to morphine, and this effect was reversed by the opiate receptor antagonist naloxone. Collectively these findings suggest that $C B_{1}$ receptors modulate opiate reward through the ventral striatopallidal projection and that the modulation of this projection system may be involved in the reciprocal behavioral effects between cannabinoids, and opioids.
\end{abstract}

Neuropsychopharmacology (2006) 31, 804-8I3. doi:I0.1038/sj.npp. 1 300848; published online 3 August 2005

Keywords: CB, receptors; SR I4I7I6A; morphine; heroin self-administration; GABA microdialysis; rat

\section{INTRODUCTION}

There is accumulating evidence that cannabinoid- $1\left(\mathrm{CB}_{1}\right)$ receptors are involved in mediating the rewarding properties of opiates. For example, genetic ablation of $\mathrm{CB}_{1}$ receptors in mice greatly reduces both opiate self-administration (Ledent et al, 1999; Cossu et al, 2001) and opiateinduced conditioned place preference (Martin et al, 2000; Rice et al, 2002). Similarly, administration of the selective $\mathrm{CB}_{1}$ receptor antagonist SR 141716A (Rimonabant) attenuates both morphine-induced conditioned place preference (Mas-Nieto et al, 2001) and heroin self-administration in rodents (Navarro et al, 2001; Caillé and Parsons, 2003; De Vries et al, 2003; Solinas et al, 2003). In addition, it has been shown that the reinforcing and motivational effects of heroin-paired stimuli are mediated, at least in part, by

*Correspondence: Dr LH Parsons, Department of Neuropharmacology, CVN-7, The Scripps Research Institute, 10550 North Torrey Pines Road, La Jolla, CA 92037, USA, Tel: + I 858784 7413, Fax: + I 858784 7405, E-mail: Iparsons@scripps.edu

Received 6 December 2004; revised 17 March 2005; accepted 18 March 2005

Online publication: 23 June 2005 at http://www.acnp.org/citations/ Npp062305040567/default.pdf activation of cannabinoid $\mathrm{CB}_{1}$ receptors (De Vries et al, 2003; Fattore et al, 2003). However, little is known regarding the neurobiological mechanisms through which $\mathrm{CB}_{1}$ receptors modulate opiate reinforcement.

Numerous studies have implicated the nucleus accumbens (NAC) as a neuroanatomical substrate involved in mediating opiate reward. For example, opiate infusions directly into the NAC of rodents induce conditioned place preference (Van Der Kooy et al, 1982) and support operant self-administration behavior (Olds, 1982; David et al, 2002). Conversely, intra-NAC opioid antagonist administration decreases the reinforcing effects of intravenous heroin (Vaccarino et al, 1985). Intra-ventral tegmental area opiate administration has been shown to inhibit GABAergic interneuronal input to dopamine (DA) cells, thereby increasing the firing of midbrain DA cells that terminate in the NAC (Johnson and North, 1992; Wise et al, 1995; Xi and Stein, 2000) and increasing NAC DA release (Hemby et al, 1995; Pontieri et al, 1995; Tanda et al, 1997; Xi and Stein, 1999). It has been postulated that this process contributes to the positive reinforcing effects of opiates. In a similar manner, $\mathrm{CB}_{1}$ receptor activation increases $\mathrm{NAC}$ DA release (French et al, 1997; Tanda et al, 1997; Gessa et al, 1998a) and accordingly it may be hypothesized that the 
modulation of opiate reward by $\mathrm{CB}_{1}$ receptors involves a dopaminergic link. However, several lines of evidence suggest that opiate reward is mediated in part through DA-independent mechanisms (Pettit et al, 1984; Gerrits and Van Ree, 1996; Shippenberg and Elmer, 1998; Platt et al, 2001 ) and the reduction in opiate self-administration induced by the $\mathrm{CB}_{1}$ antagonist SR $141716 \mathrm{~A}$ does not appear to involve a dopaminergic link in the NAC (Caille and Parsons, 2003).

An additional neural substrate in the mediation of opiate reward is the ventromedial ventral pallidum (VP). The VP receives a dense GABAergic input from the NAC (Groenewegen and Russchen, 1984; Chang and Kitai, 1985); while the NAC shell projects to the ventromedial part of the VP, the NAC core projects mainly to the dorsolateral part of the VP. Opiates strongly inhibit the spontaneous activity of the NAC GABAergic neurons (Hakan and Henriksen, 1989; Bardo, 1998; Lee et al, 1999; Xi and Stein, 2000, 2002) thereby reducing VP GABA efflux (Caillé and Parsons, 2004). The resultant disinhibition of the VP is thought to contribute to the positive reinforcing effects of opiates. Accordingly, it has been shown that the reinforcing properties of heroin self-administration are blocked by pharmacologically-induced increases in VP GABA levels (Bardo, 1998; Xi and Stein, 2000, 2002) and that intra-VP injections of a $\mu$-agonist produced reward increases (Johnson et al, 1993). Moreover, electrical stimulation of the VP produces a rewarding effect comparable to that produced by stimulating the ventral tegmental area, lateral hypothalamus, or amygdala (Panagis et al, 1995). $\mathrm{CB}_{1}$ receptors are localized in both the NAC (Herkenham et al, 1991; Robbe et al, 2001) and the VP (Herkenham et al, 1991), and thus it is possible that these receptors participate in the mediation of opiate reward by modulating the activity of the accumbal-pallidal GABA projection.

A recent examination of $\mathrm{CB}_{1}$ receptor distribution in the NAC by Pickel et al (2004) supports this possibility. Using electron microscopic immunocytochemistry, this study showed a major presynaptic distribution of $\mathrm{CB}_{1}$ receptors on terminals forming excitatory-type synapses and $\mathrm{CB}_{1}$ receptors on somata and dendrites of presumed GABAergic projection neurons in both the NAC shell and core, indicating a significantly higher number of $\mathrm{CB}_{1}$-immunogold particles in the NAC shell than in the NAC core. Interestingly, in many instances $\mathrm{CB}_{1}$ receptors were colocalized with $\mu$-opioid receptors within the same or synaptically linked neurons in the NAC shell and core (Pickel et al, 2004). Based on these collective findings it may be hypothesized that $\mathrm{CB}_{1}$ receptors participate in the mediation of opiate reward by modulating the effect of opiates on the activity of both NAC core and shell striatopallidal GABAergic projections.

The present experiments tested this hypothesis by investigating alterations in morphine-induced decreases in VP GABA efflux induced by pretreatment with the $\mathrm{CB}_{1}$ receptor antagonist SR 141716A. To evaluate a potential influence of DA input to the striatopallidal GABA system, the effects of SR 141716A on morphine-induced increases in NAC DA were also characterized. Although recent investigations indicate that $\mathrm{CB}_{1}$ receptor stimulation modulates the reinforcing properties of cocaine (Vlachou et al, 2003) and reinstates cocaine-seeking behavior (De Vries et al,
2001), a large number of studies show that $\mathrm{CB}_{1}$ receptor blockade alters opiate-, but not psychostimulant-maintained self-administration (Fattore et al, 1999; Ledent et al, 1999; Cossu et al, 2001; Vlachou et al, 2003). Thus, the effect of SR $141716 \mathrm{~A}$ on cocaine self-administration and cocaine-induced alterations in NAC DA and VP GABA efflux were also evaluated. Further, the influence of bilateral microinfusions of SR 141716A into the NAC or VP on heroin self-administration behavior was tested in an effort to identify the locus through which $\mathrm{CB}_{1}$ receptors modulate opiate reinforcement. Finally, the reciprocity of the interaction was studied by examining the ability of the opioid receptor antagonist naloxone to block the effects of the $\mathrm{CB}_{1}$ receptor agonist WIN55,212 on VP GABA efflux. Our findings indicate that $\mathrm{CB}_{1}$ receptors participate in opiate-, but not cocaine-induced decreases in VP GABA efflux through a DA-independent mechanism, and that intra-NAC SR 141716A administration attenuates the reinforcing effects of heroin selfadministration.

\section{MATERIALS AND METHODS}

\section{Subjects}

A total of 114 male Wistar rats $(300 \mathrm{~g}$, Charles River, Wilmington, MA) were used. All animals were housed in groups of three in a temperature-controlled vivarium $\left(22^{\circ} \mathrm{C}\right)$ with a $12 \mathrm{~h}$ light/dark cycle (lights on at 0800 ), and given ad libitum access to food and water. The studies were conducted in accordance with the Guide for Care and Use of Laboratory Animals provided by the National Institutes of Health.

\section{Drugs and Reagents}

Morphine sulfate, heroin hydrochloride, and cocaine hydrochloride were obtained from the National Institute on Drug Abuse (Washington, DC, USA). SR 141716A was generously provided by the National Institute of Mental Health Chemical Synthesis and Drug Supply Program (Washington, DC, USA). Naloxone, WIN 55,212-2 and all other reagents and neurotransmitter standards were obtained from Sigma (St Louis, MO, USA). Morphine, heroin, cocaine, and naloxone were dissolved in a vehicle of sterile $0.9 \%$ saline. SR $141716 \mathrm{~A}$ and WIN 55,212-2 were dissolved in a vehicle of ethanol: emulphor: saline $(1: 1: 18)$.

\section{Surgery}

Intracerebral microdialysis. Anesthetized animals (isoflurane $1.5-2.0 \%$ vapor) were implanted with a microdialysis guide cannula (21 gauge, Plastics One, Roanoke, VA, USA) aimed at either the NAC shell (from bregma: AP, $+1.6 \mathrm{~mm}$, ML, $\pm 0.8 \mathrm{~mm}$, and DV, $-6.0 \mathrm{~mm}$ ) or the VP (from bregma: $\mathrm{AP},-0.6 \mathrm{~mm}, \mathrm{ML}, \pm 2.2 \mathrm{~mm}$, and DV, $-6.7 \mathrm{~mm}$ ) (Paxinos and Watson, 1998) and cemented to the skull. All animals were permitted a minimum of 5 days of postsurgical recovery prior to experimentation. In Figure 1, the corresponding probe placements for both structures are presented (see Histology for more detailed description of the range of placements in these experiments). 

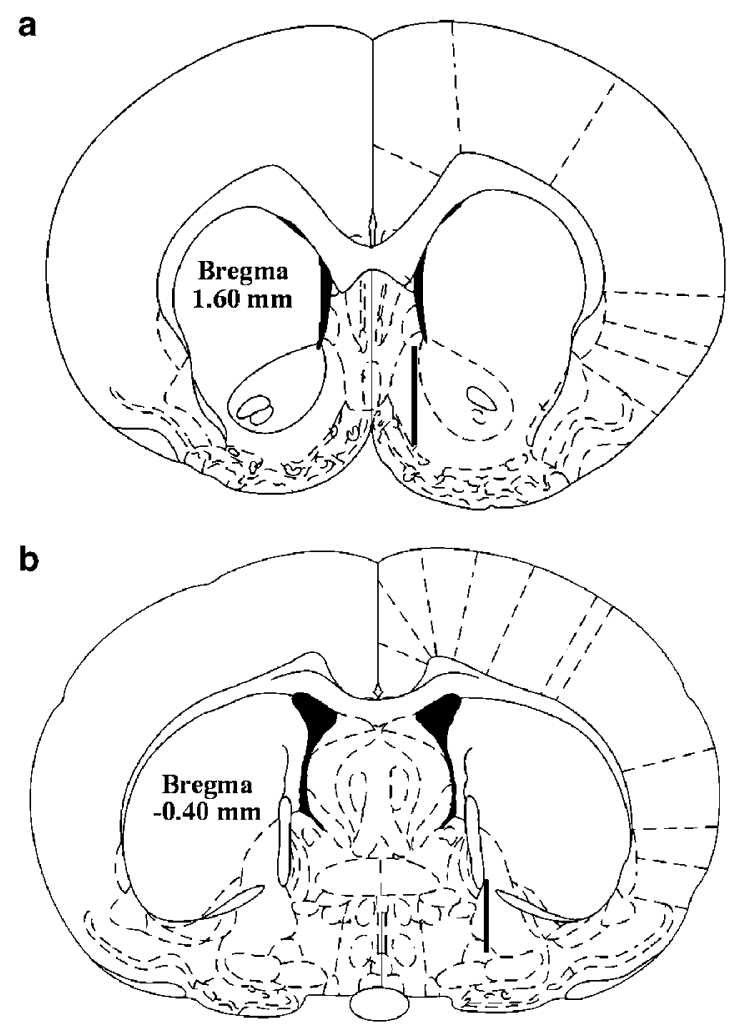

Figure I Schematic representation of the standard location of the 2-mm and the $1.5-\mathrm{mm}$ dialysis probe membranes within the nucleus accumbens shell $(n=4 I)$ and the ventral pallidum $(n=52)$ respectively. Distances shown are in mm from bregma (adapted from Paxinos and Watson, 1998).

Intravenous self-administration. In all, 21 rats were prepared with chronic silastic jugular catheters under isoflurane anesthesia (1.5-2.0\%) as described elsewhere (Caine et al, 1993). At the time of surgery, 14 of the animals were also stereotaxically implanted with bilateral 22-gauge, $12 \mathrm{~mm}$ stainless-steel guide cannulae that terminated $2 \mathrm{~mm}$ above the NAC 'shore' (from bregma: AP, $+1.7 \mathrm{~mm}, \mathrm{ML}$, $\pm 2.0 \mathrm{~mm}$ and $\mathrm{DV},-5.0 ; n=7$ ) or the VP (from bregma: $\mathrm{AP},-0.6 \mathrm{~mm}, \mathrm{ML}, \pm 2.2 \mathrm{~mm}$ and $\mathrm{DV},-5.6 \mathrm{~mm} ; n=7)$ and cemented to the skull. Catheters were flushed daily with sterile heparinized saline (30 USP $\mathrm{U} / \mathrm{ml}$ ) and the animals were allowed a minimum of seven postoperative recovery days prior to the initiation of self-administration training.

\section{In Vivo Microdialysis}

Approximately $3 \mathrm{~h}$ prior to the start of microdialysis, animals were lightly anesthetized (1.5-2.0\% isoflurane), and microdialysis probes were inserted through the guidecannulae. Microdialysis probes were constructed as described previously (Frantz et al, 2002) and employed an active membrane length that extended either $1.5 \mathrm{~mm}$ (for the VP) or $2 \mathrm{~mm}$ (for the NAC) beyond the end of the guide cannula. After probe implantation, artificial cerebral spinal fluid (aCSF, see Frantz et al, 2002 for details) was perfused at a flow-rate of either $0.3 \mu \mathrm{l} / \mathrm{min}$ for NAC DA analysis or $0.6 \mu \mathrm{l} / \mathrm{min}$ for VP GABA analysis for the duration of the experiment. Dialysate samples were collected at 10 -min intervals during the experiments, and frozen at $-70^{\circ} \mathrm{C}$ until assayed for DA content by high-performance liquid chromatography (HPLC) with electrochemical detection (Frantz et al, 2002) or for GABA content by capillary electrophoresis-coupled laser-induced fluorescence (CE-LIF; Roberto et al, 2004).

\section{Operant Self-Administration}

The self-administration chambers consisted of operant boxes enclosed in sound-attenuating, ventilated environmental cubicles (Frantz et al, 2002). Drug self-administration training was conducted in $3 \mathrm{~h}$ sessions 6 days per week. At the start of each session the operant lever was extended into the chamber, and lever pressing was reinforced by the intravenous delivery of $0.1 \mathrm{ml}$ of a drug solution on a fixedratio (FR) time out 20 -s (TO20) schedule of reinforcement. Heroin self-administration training and testing was conducted under an FR1 schedule of reinforcement with a unit dose of $0.02 \mathrm{mg} /$ infusion. Cocaine self-administration training and testing were conducted under an FR5 schedule of reinforcement with a unit dose of $0.125 \mathrm{mg}$ /infusion. An FR5 schedule of reinforcement was employed for cocaine self-administration as this higher response requirement allows for the evaluation of the temporal proximity of leverpressing activity with reinforcer delivery, with higher response rates immediately prior to reinforcer delivery being indicative of goal-directed behavior. This is particularly important with psychomotor-stimulant reinforcers as motor activation and stereotypy can compromise controlled operant performance. However, the use of high-ratio requirements typically reduces opiate self-administration. As such, a continuous reinforcement schedule was employed for heroin self-administration to avoid a confounding 'floor effect' while evaluating SR 141716A that was anticipated to reduced heroin intake. For each drug, training continued until the total number of infusions per session stabilized to within $\pm 10 \%$ of the mean for 3 consecutive days (baseline criterion).

\section{Intracerebral Injection Procedure}

Stylets were removed from the cannulae and bilateral injectors (33 gauge) were inserted, extending $2 \mathrm{~mm}$ beyond the tip of the guide cannulae. Infusions $(1 \mu \mathrm{l})$ were made over a $2 \mathrm{~min}$ period, followed by an additional $1 \mathrm{~min}$ to allow for drug diffusion prior to injector removal. Subsequently, the stylets were replaced and the rats were allowed immediate access to intravenous heroin self-administration.

\section{Experimental Design}

Experiment 1: Effect of SR 141716A on morphine-induced decreases in VP GABA efflux, and morphine-induced increases in NAC shell DA efflux. All animals in this experiment were implanted with a single microdialysis probe in either the ventromedial VP or NAC shell. Following the collection of three baseline samples, each animal received an intraperitoneal drug pretreatment followed $30 \mathrm{~min}$ later by a morphine challenge injection $(3 \mathrm{mg} / \mathrm{kg}$, s.c.) and an additional $180 \mathrm{~min}$ of dialysate collection. The drug pretreatments were vehicle (SR0; 
$n=6(\mathrm{VP})$ and $n=8(\mathrm{NAC})) ; 1 \mathrm{mg} / \mathrm{kg}$ SR $141716 \mathrm{~A}$ (SR 1 ; $n=6(\mathrm{VP})$ and $n=8(\mathrm{NAC})$ ) or $3 \mathrm{mg} / \mathrm{kg}$ SR 141716A (SR3; $n=7$ (VP) and $n=10$ (NAC)). Control groups received SR3 $(n=5$ (VP) and $n=5(\mathrm{NAC})$ ) followed by a saline injection.

Experiment 2: Effect of SR 141716A on cocaine-induced decreases in VP GABA efflux, and cocaine-induced increases in NAC shell DA efflux. As in Experiment 1, all animals in this experiment were implanted with a single microdialysis probe in either the ventromedial VP or NAC shell. Following the collection of three baseline samples, each animal received an intraperitoneal drug pretreatment followed $30 \mathrm{~min}$ later by a cocaine challenge injection $(10 \mathrm{mg} / \mathrm{kg}$, i.p.) and an additional $180 \mathrm{~min}$ of dialysate collection. The drug pretreatments were vehicle (SR0; $n=5$ (VP) and $n=5$ (NAC)) or $3 \mathrm{mg} / \mathrm{kg}$ SR 141716A (SR3; $n=5$ (VP) and $n=5$ (NAC)).

Experiment 3: Effect of intra-VP and intra-NAC SR $141716 \mathrm{~A}$ administration on intravenous heroin selfadministration. To establish stable patterns of operant heroin intake animals were allowed daily access to heroin self-administration for $3 \mathrm{~h}$ /day for 21 days as described above. Subsequently, alterations in heroin self-administration induced by SR 141716A microinfusions (veh, 1 and $3 \mu \mathrm{g} / \mathrm{side})$ into either the NAC ( $n=7$; injector placement in the 'shore') or VP $(n=7)$ were tested using a withinsubjects repeated measures design, with the order of drug presentation randomized between subjects. The baseline criterion for stable self-administration behavior was established between each pretreatment test.

Experiment 4: Effect of SR 141716A pretreatment on intravenous cocaine self-administration. To establish stable patterns of operant cocaine $(0.125 \mathrm{mg} /$ infusion $)$ intake, animals were allowed daily access to drug selfadministration on an FR5 schedule of reinforcement for $3 \mathrm{~h} /$ day for 21-33 days as described elsewhere (Frantz et al, 2002). Once stable patterns of self-administration were established, the effect of pretreatment with SR 141716A (veh, 1 and $3 \mathrm{mg} / \mathrm{kg}$, i.p.) on cocaine self-administration was tested using a within-subjects repeated measures design $(n=7)$, with the order of dose presentation randomized between subjects. The baseline criterion for stable selfadministration behavior was established between each pretreatment test.

Experiment 5: Effect of WIN 55,212-2 on VP GABA efflux, and reversal of WIN 55,212-2 effect by naloxone. All animals in this experiment were implanted with a single microdialysis probe in the ventromedial VP. Following the collection of three baseline samples, each animal received an intraperitoneal drug pretreatment followed 10 min later by a WIN $55,212-2$ challenge injection $(5 \mathrm{mg} / \mathrm{kg}$, i.p., dose selected based on the previously published reports Gessa et al, 1998b; Tzavara et al, 2003) and an additional $180 \mathrm{~min}$ of dialysate collection. The drug pretreatments were vehicle (NAL0; $n=8)$ or $1 \mathrm{mg} / \mathrm{kg}$ s.c. naloxone (NAL1; $n=6$ ). An additional control group received NAL1 $(n=4)$ followed by a saline injection.

\section{Histology}

After each experiment, the rats were euthanized by isoflurane overdose and the brain was removed and immediately frozen on dry ice. Subsequently, the brain was mounted on a cryostat and sliced into $50 \mu \mathrm{m}$ sections. Both probe and injector tip placements were then verified; all active probe membranes were located within the following stereotaxic boundaries as described by Paxinos and Watson (1998) from bregma: VP, AP -0.4 to 0.7 , ML \pm 1.8 to 2.2 , DV -8.2 to 9.0 ; NAC shell, AP +1.6 to 1.9 , $\mathrm{ML} \pm 0.6$ to $1.2, \mathrm{DV}-7.6$ to -8.2 . Only those subjects with accurate placement were included in the final data analyses.

\section{Data Analysis}

Drug self-administration behavior was expressed as the percent change in the total number of reinforcers earned in each drug pretreatment test relative to the average number of reinforcers earned over three baseline sessions that preceded the pretreatment test day. These percent change values for drug self-administration behavior were analyzed by repeated measures analysis of variance (ANOVA), with SR 141716A dose as the within-subjects factor.

Between-group differences in baseline microdialysate DA or GABA concentrations were first compared by ANOVA. Following confirmation of no group differences in baseline $\mathrm{DA}$ and GABA concentration, the data for each animal were converted to the percent change from the average baseline concentration obtained prior to the pretreatment injection. The temporal effect of drug pretreatment on morphine-, cocaine- or WIN 55,212-2-induced changes in dialysate GABA or DA levels was then evaluated using ANOVA with repeated measures over time and pretreatment dose as the between-subjects factor. Area under the curve (AUC) measures were used for comparison of overall pretreatment effects on morphine-, cocaine- or WIN 55,212-2-induced neurochemical events. The AUC was calculated for each animal by subtracting 100 from the percent of baseline value for each data point, and subsequently summing all data points collected during the post-morphine, -cocaine or -WIN 55,212-2 period of dialysate sampling. Significant differences in AUC measures were determined using ANOVA with pretreatment dose as the between-subjects factor. In each case, post hoc comparisons were made using Fisher's PLSD.

\section{RESULTS}

\section{Experiment 1: Effect of SR 141716A on Morphine-Induced Decreases in VP GABA Efflux, and Morphine-Induced Increases in NAC Shell DA Efflux}

VP GABA. Baseline GABA concentrations in VP dialysates did not differ between pretreatment groups $(\mathrm{F}(2,16)=1.69$, NS) and were as follows: SR0, $38.95 \pm 7.28 \mathrm{nM;} \mathrm{SR1,}$ $55.00 \pm 4.13 \mathrm{nM}$; SR3, $39.25 \pm 8.15 \mathrm{nM}$. In vehicle-pretreated animals morphine administration induced a significant decrease $(F(18,90)=1.88, P<0.02)$ in dialysate GABA levels that began within the first $20 \mathrm{~min}$ after the injection and persisted for approximately $150 \mathrm{~min}$ (Figure 2a). Pretreatment with the $\mathrm{CB}_{1}$ antagonist SR 141716A dose-dependently 

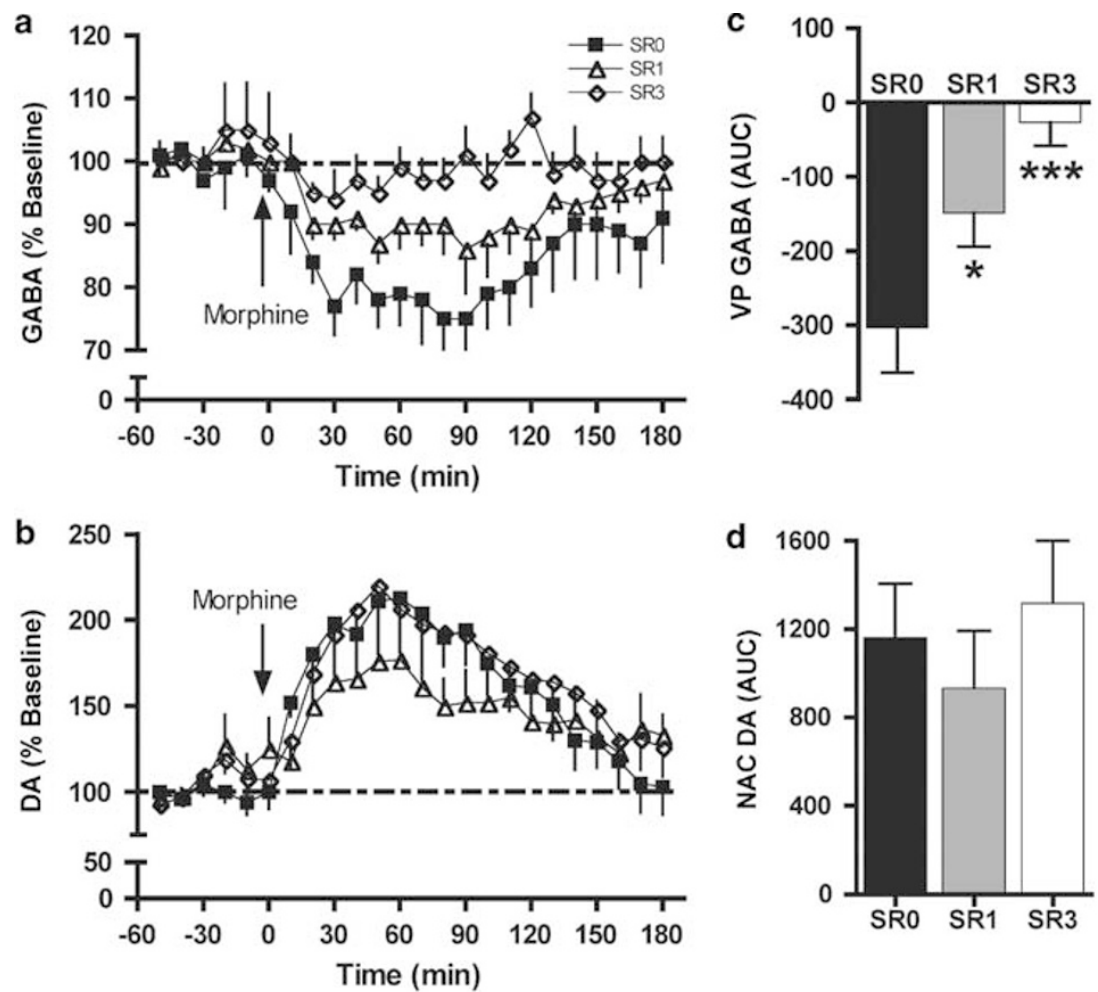

Figure 2 Effect of SR I4I7I6A pretreatment on (a) the decreased GABA efflux in the VP and (b) increased interstitial DA in the NAC shell associated with an acute morphine injection ( $3 \mathrm{mg} / \mathrm{kg}$; injection indicated by arrow). Data are expressed as the percentage change from baseline levels (mean \pm SEM). The AUC data show that although SR I4I7I6A pretreatment dose-dependently blocked morphine-induced decreases in VP GABA efflux (c), there was no significant effect of SR I4I7I6A in morphine-induced increase in NAC shell DA levels (d). The pretreatment doses of SR I4I7I6A are as follows: vehicle (SR0), I mg/kg (SRI) and $3 \mathrm{mg} / \mathrm{kg}$ (SR3). Asterisks denote significant differences from vehicle control as determined by Fisher's PLSD post hoc test (*P<0.05, $* * * P<0.001)$.

blocked the effect of morphine on VP GABA efflux $(\mathrm{F}(2,16)=9.15, P<0.005)$ (Figure $2 \mathrm{c}$ ). When administered in the absence of morphine there was no significant effect of SR 141716A on VP GABA efflux $(\mathrm{F}(18,72)=0.36$, NS; data not shown).

NAC DA. Baseline DA concentrations in NAC shell dialysates did not differ between pretreatment groups $(\mathrm{F}(2,23)=0.69, \mathrm{NS})$ and were as follows: SR0, $1.41 \pm$ $0.23 \mathrm{nM}$; SR1, $1.68 \pm 0.31 \mathrm{nM}$; SR3, $1.86 \pm 0.28 \mathrm{nM}$. In vehiclepretreated animals morphine administration induced a significant increase $(\mathrm{F}(18,126)=14.68, P<0.0001)$ in dialysate DA levels that began within the first 20 min after the injection and persisted for approximately $150 \mathrm{~min}$ (Figure $2 b$ ). There was no significant effect of SR 141716A pretreatment on morphine-induced increases in NAC DA efflux $(F(2,23)=0.53$, NS) (Figure $2 \mathrm{~d}$ ). When administered in the absence of morphine there was no significant effect of SR $141716 \mathrm{~A}$ on NAC DA efflux $(\mathrm{F}(18,72)=1.25$, NS; data not shown).

\section{Experiment 2: Effect of SR 141716A on Cocaine-Induced Decreases in VP GABA Efflux, and Cocaine-Induced Increases in NAC Shell DA Efflux}

VP GABA. Baseline GABA concentrations in VP dialysates did not differ between pretreatment groups $(\mathrm{F}(1,8)=0.06$, NS) and were $39.73 \pm 2.78$ and $40.74 \pm 3.82 \mathrm{nM}$ for the SR0 and SR3 pretreatment groups, respectively. Similar to the effect produced by morphine, cocaine induced a significant decrease $(\mathrm{F}(4,18)=4.42, P<0.0001)$ in dialysate GABA levels in vehicle-pretreated animals that began within the first $10 \mathrm{~min}$ after the injection and persisted for approximately $90 \mathrm{~min}$ (Figure 3a). However, in contrast to the effect of SR 141716A on morphine-induced decrements in VP GABA, there was no significant effect of this $\mathrm{CB}_{1}$ antagonist on cocaine-induced reductions in VP GABA $(F(1,8)=0.02$, NS) (See Figure 3c).

NAC DA. Baseline DA concentrations in NAC shell dialysates did not differ between pretreatment groups $(\mathrm{F}(1,8)=0.80$, NS $)$ and were $2.7 \pm 0.2$ and $2.4 \pm 0.3 \mathrm{nM}$ for the SR0 and SR3 pretreatment groups, respectively. Cocaine administration significantly increased dialysate DA concentrations in vehicle-pretreated animals $(\mathrm{F}(12,48)=75.32$, $P<0.0001)$ and this effect was unaltered by SR $141716 \mathrm{~A}$ pretreatment $(\mathrm{F}(1,8)=0.03$, NS) (see Figure $3 \mathrm{~b}$ and $d$ ).

\section{Experiment 3: Effect of Intra-VP and Intra-NAC SR 141716A Administration on Intravenous Heroin Self-Administration}

During the final three self-administration sessions prior to the pretreatment tests animals in the VP group obtained an average of $15 \pm 1$ heroin reinforcers per session, and animals in the NAC group obtained an average of $19 \pm 2$ heroin 


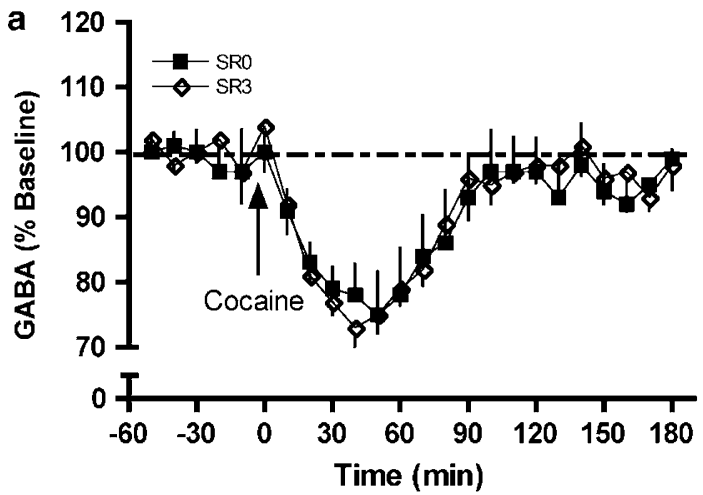

C
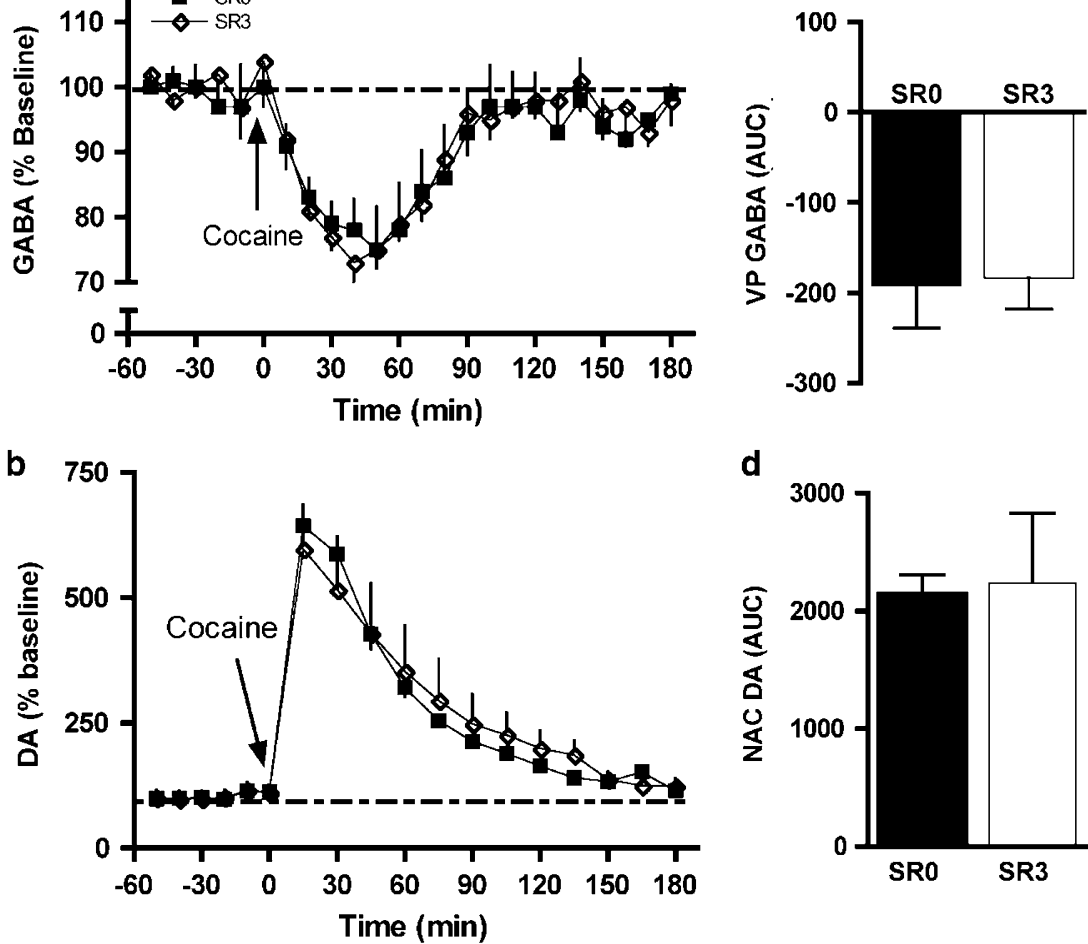

d

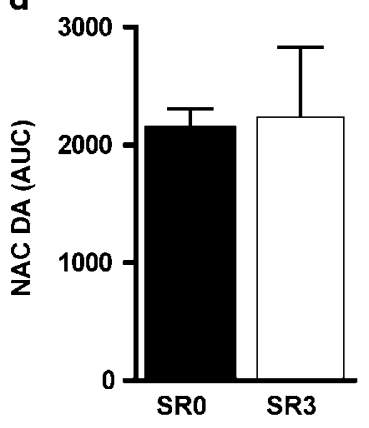

Figure 3 Effect of SR I4I7I6A pretreatment on (a) the decreased GABA efflux in the VP and (b) increased interstitial DA in the NAC shell that are associated with an acute cocaine injection ( $10 \mathrm{mg} / \mathrm{kg}$; injection indicated by arrow). Data are expressed as the percentage change from baseline levels (mean \pm SEM). The AUC data show that SR 141716A did not alter either VP GABA efflux (c) or DA levels in the NAC shell (d). The pretreatment doses of SR I4I7I6A are as follow: vehicle (SRO) and $3 \mathrm{mg} / \mathrm{kg}$ (SR3).

reinforcers. This baseline level of drug intake was stable within each group between pretreatment tests. Heroin selfadministration was significantly reduced by intra-NAC SR $141716 \mathrm{~A}$ administration $(\mathrm{F}(2,12)=4.52, \quad P<0.05)$. Pretreatment with 1 or $3 \mu \mathrm{g}$ SR $141716 \mathrm{~A} /$ side significantly decreased heroin intake to $72 \pm 10 \%(1 \mu \mathrm{g} /$ side $)$ and $71 \pm 11 \%$ $(3 \mu \mathrm{g} / \mathrm{side})$ of baseline self-administration levels (both doses $P<0.05)$ (Figure $4 \mathrm{a}$ ). In contrast, there was no significant effect of intra-VP SR 141716A administration on heroin self-administration behavior $(\mathrm{F}(2,12)=0.33$, NS). Location of injector tips are presented in Figure $4 \mathrm{~b}$.

\section{Experiment 4: Effect of SR 141716A Pretreatment on Intravenous Cocaine Self-Administration}

Baseline cocaine intake prior to SR 141716 A testing was $70 \pm 8.6$ infusions per $3 \mathrm{~h}$ session. Consistent with recent findings by others (De Vries et al, 2001) pretreatment with SR 141716 A produced no significant alteration in cocaine self-administration $(\mathrm{F}(2,12)=0.224 ; \mathrm{NS})$. Cocaine selfadministration was $106 \pm 3,111 \pm 7$, and $109 \pm 8 \%$ of baseline levels following pretreatment with vehicle, 1 and $3 \mathrm{mg} /$ kg SR 141716A, respectively (data not presented in graphic or tabular form). The inability of SR 141716A to alter cocaine self-administration is in contrast to the significant reduction in operant responding for heroin under both FR and progressive-ratio schedules of reinforcement induced by these same SR 141716A doses previously observed both in our laboratory (Caillé and Parsons, 2003) and by others (De Vries et al, 2003; Solinas et al, 2003).

Experiment 5: Effect of WIN 55,212-2 on VP GABA Efflux, and Reversal of WIN 55,212-2 Effect by Naloxone

Baseline GABA concentrations in VP dialysates were $40.14 \pm 1.64,49.72 \pm 2.95$ and $50.55 \pm 1.54 \mathrm{nM}$ for the VEHWIN, NAL-WIN, and NAL-VEH groups, respectively, and there were no significant differences between groups in baseline levels $(\mathrm{F}(2,15)=1.53$, NS). In vehicle-pretreated animals WIN 55,212-2 administration induced a significant decrease $(\mathrm{F}(18,126)=8.57, P<0.001)$ in dialysate GABA levels that began within the first $20 \mathrm{~min}$ after the injection and persisted for approximately $150 \mathrm{~min}$ (Figure 5a). Pretreatment with the nonselective opioid receptor antagonist naloxone $(1 \mathrm{mg} / \mathrm{kg})$ significantly blocked the effect of WIN 55,212-2 on VP GABA efflux $(\mathrm{F}(1,12)=7.17, P<0.02)$ (Figure 5b). There was no significant effect of naloxone alone on VP GABA efflux $(\mathrm{F}(18,54)=1.26$, NS; data not shown).

\section{DISCUSSION}

A growing body of evidence suggests that $C_{1}$ receptors modulate opiate but not psychostimulant reward. $\mathrm{CB}_{1}$ receptor knockout mice display significantly attenuated heroin-induced conditioned place-preference and heroin 


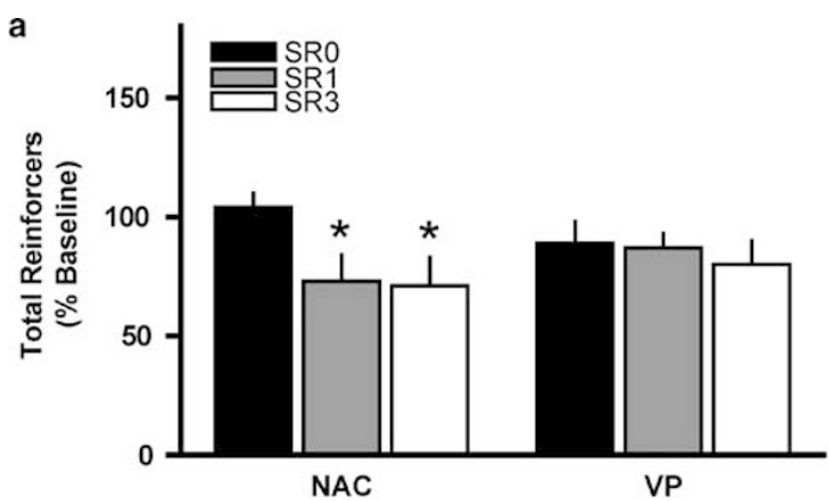

b
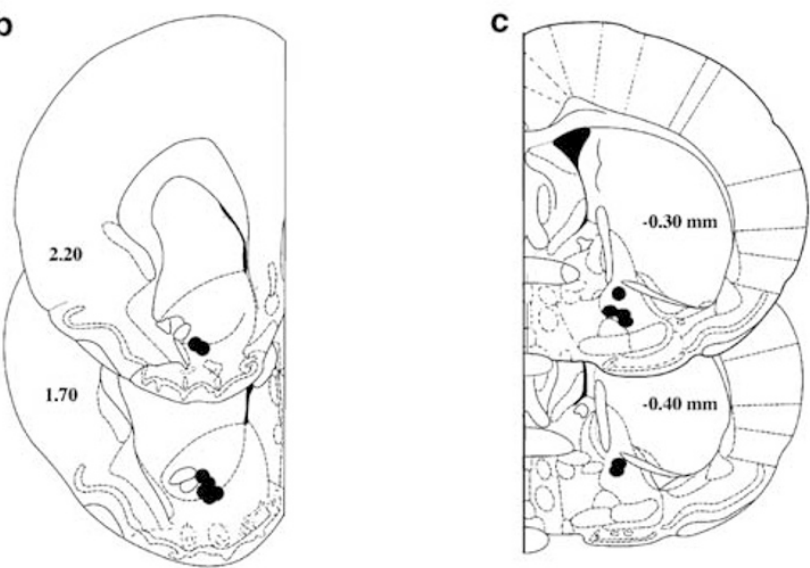

Figure 4 Effect of bilateral intra-VP and intra-NAC SR 141716A infusions on heroin self-administration (0.02 mg/infusion, FRI schedule) (a). SR 141716A administered into the nucleus accumbens (NAC), but not the ventral pallidum $(V P)$, reduced heroin self-administration behavior. The SR |4I7|6A doses were: vehicle (SRO), I $\mu \mathrm{g} / \mu \mathrm{l} / \mathrm{side}(\mathrm{SRI})$ and $3 \mu \mathrm{g} / \mu \mathrm{l} / \mathrm{side}$ (SR3). Asterisks denote significant differences from vehicle control as determined by Fisher's PLSD post hoc test $(* P<0.05)$. Schematic representation of the location of the injector tips within the NAC (b) and the VP (c). Distances are in $\mathrm{mm}$ anterior to bregma (adapted from Paxinos and Watson, 1998).
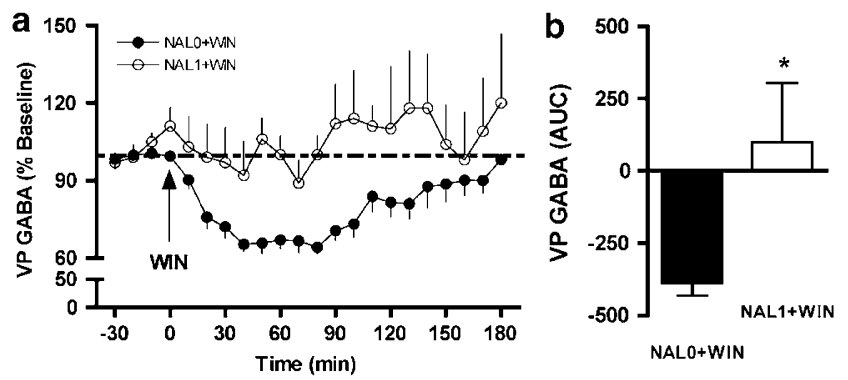

Figure 5 Effect of naloxone pretreatment on (a) decreased GABA efflux in the VP associated with an acute WIN 55.212-2 injection (5 mg/kg; injection indicate by arrow). Data are expressed as the percentage change from baseline levels (mean \pm SEM). The AUC data show that naloxone pretreatment blocked WIN-induced decreases in VP GABA efflux (b). The pretreatment doses of naloxone are as follow: vehicle (NALO) and I mg/kg (NALI). Asterisks denote significant differences from vehicle control as determined by Fisher's PLSD post hoc test (*P<0.05).

self-administration but not cocaine place conditioning or self-administration (Ledent et al, 1999; Martin et al, 2000; Cossu et al, 2001). Similarly, the $\mathrm{CB}_{1}$ receptor antagonist SR
141716A significantly reduces the reinforcing effects of heroin, but not cocaine, self-administration in rats (Fattore et al, 1999; De Vries et al, 2001; Mas-Nieto et al, 2001; Navarro et al, 2001; Caillé and Parsons, 2003; De Vries et al, 2003; Solinas et al, 2003). The present data demonstrate that SR 141716A dose-dependently reverses morphine- but not cocaine-induced decreases in VP GABA efflux within a dose range that significantly reduces opiate (Navarro et al, 2001; Caillé and Parsons, 2003; De Vries et al, 2003; Solinas et al, 2003) but not cocaine (De Vries et al, 2001) reward in rats. This effect is independent of alterations in morphineinduced increases in NAC DA efflux, and appears to be mediated by $C_{1}$ receptors in the NAC rather than the VP. Moreover, the $C_{1}$ receptor agonist WIN 55,212-2 reduced VP GABA efflux in a manner similar to morphine, and this effect was reversed by naloxone. These findings suggest that $\mathrm{CB}_{1}$ receptors modulate opiate reward through the ventral striatopallidal GABA projection and that the modulation of this projection system may be involved in the reciprocal interactions between cannabinoids and opioids.

The VP has been implicated in mediating the rewarding effects of opiates and psychostimulants (Johnson et al, 1993; Robledo and Koob, 1993; Johnson and Stellar, 1994; Gong et al, 1996; Bardo, 1998; Xi and Stein, 2000, 2002). This region receives dense GABAergic innervation from the NAC (Groenewegen and Russchen, 1984; Chang and Kitai, 1985), and both opiate and psychostimulant drugs inhibit the activity of this projection (Hakan and Henriksen, 1989; Bourdelais and Kalivas, 1990; Bardo, 1998; Lee et al, 1999; Xi and Stein, 2000, 2002; Caillé and Parsons, 2004). Consistently, both morphine and cocaine were found to significantly decrease VP GABA efflux in the present study. The inhibitory effect of morphine on VP GABA was dosedependently reversed by doses of the $\mathrm{CB}_{1}$ antagonist $\mathrm{SR}$ $141716 \mathrm{~A}$ that also significantly attenuate the breaking point of responding for heroin under a progressive-ratio schedule of reinforcement (Caillé and Parsons, 2003; De Vries et al, 2003; Solinas et al, 2003). Opiates also increase NAC DA efflux (Hemby et al, 1995; Pontieri et al, 1995) which may contribute to morphine-induced decrements in VP GABA (Yang and Mogenson, 1989; Bourdelais and Kalivas, 1992). However, SR 141716A produced no significant effect on morphine-induced increases in NAC DA, suggesting that the effects of SR 141716A on morphine-induced decrements in VP GABA occur independently of NAC DA. This is consistent with the recent observation that SR 141716Ainduced reductions in heroin reward occur through a mechanism independent of NAC DA (Caillé and Parsons, 2003). There was no significant effect of SR 141716A itself on either VP GABA efflux or NAC DA efflux, suggesting that it alters opiate-induced neurochemical events rather than simply blocking tonically active processes.

In contrast to the effects of SR $141716 \mathrm{~A}$ on opiate-induced neurochemical events and opiate-maintained behavior, the present experiments revealed no significant effect of this $\mathrm{CB}_{1}$ antagonist on cocaine-induced decrements in VP GABA, cocaine-induced increases in NAC DA or cocainemaintained operant behavior (also see De Vries et al, 2001). Since psychostimulant-induced decrements in VP GABA efflux are likely produced via increased NAC DA levels (Yang and Mogenson, 1989; Bourdelais and Kalivas, 1990, $1992)$, the inability of SR 141716 A to alter cocaine-induced 
decrements in VP GABA efflux suggests this $\mathrm{CB}_{1}$ antagonist does not alter the inhibitory effects of NAC DA on the ventral striatopallidal GABA projection. This further supports the assertion that SR 141716A-induced reductions in opiate reward do not involve a NAC DA link.

$\mathrm{CB}_{1}$ receptors are present in both the $\mathrm{VP}$ and the NAC (Herkenham et al, 1991; Pickel et al, 2004) and thus the effect of SR 141716A on morphine-induced decrements in VP GABA efflux may be produced by $\mathrm{CB}_{1}$ receptors in either of these regions. Since $C_{1}$ receptors exert a negative influence on GABA release (Hajos et al, 2000) blockade of VP $\mathrm{CB}_{1}$ receptors may reverse morphine-induced decrements in VP GABA efflux, in turn attenuating opiate reward (Bardo, 1998; Xi and Stein, 2000, 2002). $\mathrm{CB}_{1}$ receptors in the NAC modulate the release of GABA and glutamate (Hoffman and Lupica, 2001; Pistis et al, 2002; Robbe et al, 2003) and therefore these receptors may modulate opiate reward by influencing the activity of striatopallidal projection neurons (Napier and Mitrovic, 1999). To investigate the neural locus through which $\mathrm{CB}_{1}$ receptors modulate opiate reward, the effect of SR 141716A infusions into the VP or NAC on heroin self-administration was investigated. Previous studies have shown that peripheral SR 141716A administration dose-dependently reduces operant responding for $0.02 \mathrm{mg} /$ infusion heroin under both fixed- and progressive-ratio schedules of reinforcement (Caillé and Parsons, 2003; De Vries et al, 2003; Solinas et al, 2003). These observations suggest that SR 141716A decreases the reinforcing efficacy of intravenous heroin. In the present study, intra-NAC SR 141716A infusions produced a similar and significant decrease in operant responding for $0.02 \mathrm{mg} /$ infusion heroin, while intra-VP infusions of this same SR $141716 \mathrm{~A}$ dose range did not alter heroin intake. This suggests that the NAC is an important locus for the modulation of opiate self-administration by $\mathrm{CB}_{1}$ receptors, consistent with the proposed importance of this brain region in the mediation of opiate reward (see Introduction) and several lines of evidence which point toward convergent actions of $\mu$-opioid- and $\mathrm{CB}_{1}$ receptors in the NAC (Hoffman and Lupica, 2001; Manzoni and Bockaert, 2001; Pickel et al, 2004). Moreover, GABAergic medium spiny neurons are the predominant type of efferent neurons in the NAC core and shell (Sesack and Pickel, 1990; Smith and Bolam, 1990) and both bear $\mathrm{CB}_{1}$ receptors (Pickel et al, 2004). Altogether, these findings suggest an important influence of $\mathrm{NAC} \mathrm{CB}_{1}$ receptors in the regulation of VP GABA transmission and the reinforcing properties of opiates. However, the relative involvement of the core and shell subregions cannot be evaluated by the present experiments as the injectors were placed in the 'shore' thereby allowing SR141716A diffusion into both the core and shell. It should also be noted that the VP receives inputs from a number of regions besides the NAC (for review see Groenewegen et al, 1999; Napier and Mitrovic, 1999), many of which also contain $\mathrm{CB}_{1}$ receptors. This leaves open the likely possibility that regions other than the NAC participate in the $\mathrm{CB}_{1}$ modulation of opiateinduced neurochemical events in the VP. Further, opioids exert direct effects in the VP (Napier and Mitrovic, 1999) and this may explain in part why blockade of $\mathrm{NAC} \mathrm{CB}_{1}$ receptors did not abolish completely heroin self-administration.
The neural processes through which $\mathrm{NAC}^{\mathrm{C}} \mathrm{B}_{1}$ receptors alter opiate-induced decrements in VP GABA efflux and opiate reinforcement are presently unknown, though several mechanisms may be postulated. For example, $\mathrm{CB}_{1}$ and opiate receptors might interact at the level of their signal transduction pathways as both classes of receptors are coupled to Gi/Go-proteins and their stimulation modulates cAMP-dependent and MAP kinase pathways (Matsuda et al, 1990; Childers et al, 1992; Reisine et al, 1996). In addition, $\mathrm{CB}_{1}$ receptor activation drastically reduces stimulated glutamate release in the NAC (Pistis et al, 2002) through the activation of presynaptic $\mathrm{CB}_{1}$ receptors (Robbe et al, 2002; Robbe et al, 2003). Moreover, $\mathrm{CB}_{1}$ receptors have been localized presynaptically on excitatory-type neurons that synapse with medium spiny neurons in the NAC (Pickel et al, 2004) whose postsynaptic activity can be suppressed by opiates (Childers et al, 1992). Thus, removal of the inhibitory influence of $\mathrm{CB}_{1}$ receptors on these glutamate inputs (via SR 141716A administration) may serve to activate the VP GABA projection, thereby counteracting the morphine-induced decrease in VP GABA outflow.

The observation that naloxone, a $\mu$-opioid receptor antagonist, blocks the $\mathrm{CB}_{1}$ agonist-induced decrease in VP GABA, provides additional evidence of a reciprocal interaction between the cannabinoid and opioid systems in the CNS (for review see Corchero et al, 2004; Fattore et al, 2004). The interaction between the cannabinoid and opioid systems in the modulation of the accumbo-pallidal projection may be important in light of the proposed involvement of the VP in mediating drug reward, and drug-induced alterations in this interaction may contribute to neuroadaptations involved in the development of drug dependence. The mechanism(s) through which $\mu$-receptors modulate $\mathrm{CB}_{1}$ agonist-induced decrements in VP GABA efflux are presently unknown. Although our present and previous data suggest that the modulation of opiate-induced decreases in VP GABA efflux by $\mathrm{CB}_{1}$ receptors occurs independent of alterations in NAC DA, it is conceivable that the $\mu$-receptor modulation of $\mathrm{CB}_{1}$ agonist-induced neurochemical events does involve NAC DA. For example, the $\mathrm{CB}_{1}$ agonist WIN 55,212-2 increases mesolimbic DA cell firing through a naloxone-sensitive mechanism (Tanda et $a l, 1997)$ and this may influence the activity of the accumbo-pallidal GABA projection. Alternately, $\mathrm{CB}_{1}$ agonist administration is reported to increase opioid peptide release (Mason et al, 1999; Welch and Eads 1999; Valverde et al, 2001) and it is possible that this process contributes to the $\mu$-receptor-dependent modulation of VP GABA release by WIN 55,212-2. Regardless of the mechanism through which this interaction occurs, an important consideration for future work will be whether chronic opiate or cannabinoid exposure alters the responsivity of the VP to drug ingestion, and if so whether this alteration results from an adaptation of the cannabinoid-opioid interaction in this system.

In summary, the present results demonstrate that SR 141716A dose-dependently reverses morphine-, but not cocaine-induced decreases in VP GABA efflux within a dose range that significantly reduces opiate reward in rats. This effect does not appear to involve an alteration in morphineinduced increases in NAC DA efflux, or in the efficacy of increased NAC DA to inhibit the VP GABA projection. The blockade of WIN 55,212-2-induced decreases in VP GABA 
efflux by naloxone points to a reciprocal interaction between cannabinoids and opioids in the modulation of ventral pallidal activity. These findings suggest that SR $141716 \mathrm{~A}$ attenuates opiate reward by diminishing the inhibitory influence of opiates on NAC medium spiny neurons.

\section{ACKNOWLEDGEMENTS}

This manuscript is publication 16929-NP from The Scripps Research Institute. We thank David Stouffer for his excellent technical assistance and Mike Arends for editorial assistance. We also thank Drs George F Koob and Paul J Kenny for critical comments on this manuscript.

\section{REFERENCES}

Bardo MT (1998). Neuropharmacological mechanisms of drug reward: beyond dopamine in the nucleus accumbens. Crit Rev Neurobiol 12: 37-67.

Bourdelais A, Kalivas PW (1990). Amphetamine lowers extracellular GABA concentration in the ventral pallidum. Brain Res 516: 132-136.

Bourdelais A, Kalivas PW (1992). Apomorphine decreases extracellular GABA in the ventral pallidum of rats with 6-OHDA lesions in the nucleus accumbens. Brain Res 577: 306-311.

Caille S, Parsons LH (2003). SR141716A reduces the reinforcing properties of heroin but not heroin-induced increases in the nucleus accumbens in rats. Eur J Neurosci 18: 3145-3149.

Caillé S, Parsons LH (2004). Intravenous heroin self-administration decreases GABA efflux in the ventral pallidum: an in vivo microdialysis study in rats. Eur J Neurosci 20: 593-596.

Caine SB, Lintz R, Koob GF (1993). Intravenous drug selfadministration techniques in animals. In: Sahgal, A (ed). Behavioural Neuroscience: A Practical Approach. Oxford University Press, New York. pp 117-143.

Chang HT, Kitai ST (1985). Projection neurons of the nucleus accumbens: an intracellular labeling study. Brain Res 347: $112-116$.

Childers SR, Fleming L, Konkoy C, Marckel D, Pacheco M, Sexton $\mathrm{T}$ et al (1992). Opioid and cannabinoid receptor inhibition of adenylyl cyclase in brain. Ann N Y Acad Sci 654: 33-51.

Corchero J, Manzanares J, Fuentes JA (2004). Cannabinoid/opioid crosstalk in the central nervous system. Crit Rev Neurobiol 16: 159-172.

Cossu G, Ledent C, Fattore L, Imperato A, Bohme GA, Parmentier $M$ et al (2001). Cannabinoid CB1 receptor knockout mice fail to self-administer morphine but not other drugs of abuse. Behav Brain Res 118: 61-65.

David V, Durkin TP, Cazala P (2002). Differential effects of the dopamine D2/D3 receptor antagonist sulpiride on self-administration of morphine into the ventral tegmental area or the nucleus accumbens. Psychopharmacology (Berlin) 160: 307-317.

De Vries TJ, Homberg JR, Binnekade R, Raaso H, Schoffelmeer AN (2003). Cannabinoid modulation of the reinforcing and motivational properties of heroin and heroin-associated cues in rats. Psychopharmacology (Berlin) 168: 164-169.

De Vries TJ, Shaham Y, Homberg JR, Crombag H, Schuurman K, Dieben J et al (2001). A cannabinoid mechanism in relapse to cocaine seeking. Nat Med 7: 1151-1154.

Fattore L, Cossu G, Spano MS, Delana S, Fadda P, Scherma M et al (2004). Cannabinoids and reward: interactions with the opioid system. Crit Rev Neurobiol 16: 147-158.

Fattore L, Martellotta MC, Cossu G, Mascia MS, Fratta W (1999). CB1 cannabinoid receptor agonist WIN 55,212-2 decreases intravenous cocaine self-administration in rats. Behav Brain Res 104: 141-146.

Fattore L, Spano MS, Cossu G, Deiana S, Fratta W (2003). Cannabinoid mechanism in reinstatement of heroin-seeking after a long period of abstinence in rats. Eur J Neurosci 17: $1723-1726$.

Frantz KJ, Hansson KJ, Stouffer DG, Parsons LH (2002). 5-HT(6) receptor antagonism potentiates the behavioral and neurochemical effects of amphetamine but not cocaine. Neuropharmacology 42: $170-180$.

French ED, Dillon K, Wu X (1997). Cannabinoids excite dopamine neurons in the ventral tegmentum and substantia nigra. Neuroreport 8: 649-652.

Gerrits MA, Van Ree JM (1996). Effect of nucleus accumbens dopamine depletion on motivational aspects involved in initiation of cocaine and heroin self-administration in rats. Brain Res 713: 114-124.

Gessa GL, Casu MA, Carta G, Mascia MS (1998b). Cannabinoids decrease acetylcholine release in the medial-prefrontal cortex and hippocampus, reversal by SR 141716A. Eur J Pharmacol 355: 119-124.

Gessa GL, Melis M, Muntoni AL, Diana M (1998a). Cannabinoids activate mesolimbic dopamine neurons by an action on cannabinoid CB1 receptors. Eur J Pharmacol 341: 39-44.

Gong W, Neill D, Justice Jr JB (1996). Conditioned place preference and locomotor activation produced by injection of psychostimulants into ventral pallidum. Brain Res 707: 64-74.

Groenewegen HJ, Russchen FT (1984). Organization of the efferent projections of the nucleus accumbens to pallidal, hypothalamic, and mesencephalic structures: a tracing and immunohistochemical study in the cat. J Comp Neurol 223: 347-367.

Groenewegen HJ, Wright CI, Beijer AV, Voor P (1999). Convergence and segregation of ventral striatal inputs and outputs. Ann NY Acad Sci. 877: 49-63.

Hakan RL, Henriksen SJ (1989). Opiate influences on nucleus accumbens neuronal electrophysiology: dopamine and nondopamine mechanisms. J Neurosci 9: 3538-3546.

Hajos N, Katona I, Naiem SS, MacKie K, Ledent C, Mody I et al (2000). Cannabinoids inhibit hippocampal GABAergic transmission and network oscillations. Eur J Neurosci 12: 3239-3249.

Hemby SE, Martin TJ, Co C, Dworkin SI, Smith JE (1995). The effects of intravenous heroin administration on extracellular nucleus accumbens dopamine concentrations as determined by in vivo microdialysis. J Pharmacol Exp Ther 273: 591-598.

Herkenham M, Lynn AB, Johnson MR, Melvin LS, de Costa BR, Rice KC (1991). Characterization and localization of cannabinoid receptors in rat brain: a quantitative in vitro autoradiographic study. J Neurosci 11: 563-583.

Hoffman AF, Lupica CR (2001). Direct actions of cannabinoids on synaptic transmission in the nucleus accumbens: a comparison with opioids. J Neurophysiol 85: 72-83.

Johnson PI, Stellar JR (1994). Comparison of delta opiate receptor agonist induced reward and motor effects between the ventral pallidum and dorsal striatum. Neuropharmacology 33: 11711182.

Johnson PI, Stellar JR, Paul DA (1993). Regional reward differences within the ventral pallidum are revealed by microinjections of a mu opiate receptor agonist. Neuropharmacology 32: 1305-1314. Johnson SW, North RA (1992). Opioids excite dopamine neurons by hyperpolarization of local interneurons. J Neurosci 12: 483-488.

Ledent C, Valverde O, Cossu G, Petitet F, Aubert JF, Beslot F et al (1999). Unresponsiveness to cannabinoids and reduced addictive effects of opiates in CB1 receptor knockout mice. Science 283: 401-404.

Lee RS, Criado JR, Koob GF, Henriksen SJ (1999). Cellular responses of nucleus accumbens neurons to opiate-seeking behavior: I. Sustained responding during heroin self-administration. Synapse 33: 49-58. 
Manzoni OJ, Bockaert J (2001). Cannabinoids inhibit GABAergic synaptic transmission in mice nucleus accumbens. Eur $J$ Pharmacol 412: R3-R5.

Martin M, Ledent C, Parmentier M, Maldonado R, Valverde O (2000). Cocaine, but not morphine, induces conditioned place preference and sensitization to locomotor responses in CB1 knockout mice. Eur J Neurosci 12: 4038-4046.

Mas-Nieto M, Pommier B, Tzavara ET, Caneparo A, Da Nascimento S, Le Fur G et al (2001). Reduction of opioid dependence by the CB1 antagonist SR141716A in mice: evaluation of the interest in pharmacotherapy of opioid addiction. Br J Pharmacol 132: 1809-1816.

Mason Jr DJ, Lowe J, Welch SP (1999). Cannabinoid modulation of dynorphin A: correlation to cannabinoid-induced antinociception. Eur J Pharmacol 378: 237-248.

Matsuda LA, Lolait SJ, Brownstein MJ, Young AC, Bonner TI (1990). Structure of a cannabinoid receptor and functional expression of the cloned cDNA. Nature 346: 561-564.

Napier TC, Mitrovic I (1999). Opioid modulation of ventral pallidal inputs. Ann NY Acad Sci 877: 176-201.

Navarro M, Carrera MR, Fratta W, Valverde O, Cossu G, Fattore L et al (2001). Functional interaction between opioid and cannabinoid receptors in drug self-administration. J Neurosci 21: $5344-5350$.

Olds ME (1982). Reinforcing effects of morphine in the nucleus accumbens. Brain Res 237: 429-440.

Panagis G, Miliaressis E, Anagnostakis Y, Spyraki C (1995). Ventral pallidum self-stimulation: a moveable electrode mapping study. Behav Brain Res 68: 165-172.

Paxinos G, Watson C (1998). The Rat Brain in Stereotaxic Coordinates. Academic: San Diego.

Pettit HO, Ettenberg A, Bloom FE, Koob GF (1984). Destruction of dopamine in the nucleus accumbens selectively attenuates cocaine but not heroin self-administration in rats. Psychopharmacology (Berlin) 84: 167-173.

Pickel VM, Chan J, Kash TL, Rodriguez JJ, MacKie K (2004). Compartment-specific localization of cannabinoid 1 (CB1) and micro-opioid receptors in rat nucleus accumbens. Neuroscience 127: $101-112$

Pistis M, Muntoni AL, Pillolla G, Gessa GL (2002). Cannabinoids inhibit excitatory inputs to neurons in the shell of the nucleus accumbens: an in vivo electrophysiological study. Eur J Neurosci 15: $1795-1802$.

Platt DM, Rowlett JK, Spealman RD (2001). Discriminative stimulus effects of intravenous heroin and its metabolites in rhesus monkeys: opioid and dopaminergic mechanisms. J Pharmacol Exp Ther 299: 760-767.

Pontieri FE, Tanda G, Di Chiara G (1995). Intravenous cocaine, morphine, and amphetamine preferentially increase extracellular dopamine in the 'shell' as compared with the 'core' of the rat nucleus accumbens. Proc Natl Acad Sci USA 92: 12304-12308.

Reisine T, Law SF, Blake A, Tallent M (1996). Molecular mechanisms of opiate receptor coupling to $G$ proteins and effector systems. Ann NY Acad Sci 780: 168-175.

Rice OV, Gordon N, Gifford AN (2002). Conditioned place preference to morphine in cannabinoid CB1 receptor knockout mice. Brain Res 945: 135-138.

Robbe D, Alonso G, Duchamp F, Bockaert J, Manzoni OJ (2001). Localization and mechanisms of action of cannabinoid receptors at the glutamatergic synapses of the mouse nucleus accumbens. J Neurosci 21: 109-116.

Robbe D, Alonso G, Manzoni OJ (2003). Exogenous and endogenous cannabinoids control synaptic transmission in mice nucleus accumbens. Ann NY Acad Sci 1003: 212-225.
Robbe D, Kopf M, Remaury A, Bockaert J, Manzoni OJ (2002). Endogenous cannabinoids mediate long-term synaptic depression in the nucleus accumbens. Proc Natl Acad Sci USA 99: 8384-8388.

Roberto M, Schweitzer P, Madamba SG, Stouffer DG, Parsons LH, Siggins GR (2004). Acute and chronic ethanol alter glutamatergic transmission in rat central amygdala: an in vitro and in vivo analysis. J Neurosci 24: 1594-1603.

Robledo P, Koob GF (1993). Two discrete nucleus accumbens projection areas differentially mediate cocaine self-administration in the rat. Behav Brain Res 55: 159-166.

Sesack SR, Pickel VM (1990). In the rat medial nucleus accumbens, hippocampal and catecholaminergic terminals converge on spiny neurons and are in apposition to each other. Brain Res 527: 266-279.

Shippenberg TS, Elmer GI (1998). The neurobiology of opiate reinforcement. Crit Rev Neurobiol 12: 267-303.

Smith AD, Bolam JP (1990). The neural network of the basal ganglia as revealed by the study of synaptic connections of identified neurones. Trends Neurosci 13: 259-265.

Solinas M, Panlilio LV, Antoniou K, Pappas LA, Goldberg SR (2003). The cannabinoid CB1 antagonist SR-141716A, differentially alters the reinforcing effects of heroin under continuousreinforcement, fixed-ratio and progressive-ratio schedules of drug self-administration in rats. J Pharmacol Exp Ther 306: 93-102.

Tanda G, Pontieri FE, Di Chiara G (1997). Cannabinoid and heroin activation of mesolimbic dopamine transmission by a common mu1 opioid receptor mechanism. Science 276: 2048-2050.

Tzavara ET, Wade M, Nomikos GG (2003). Biphasic effects of cannabinoids on acetylcholine release in the hippocampus: site and mechanism of action. $J$ Neurosci 23: 9374-9384.

Vaccarino FJ, Bloom FE, Koob GF (1985). Blockade of nucleus accumbens opiate receptors attenuates intravenous heroin reward in the rat. Psychopharmacology (Berlin) 86: 37-42.

Valverde O, Noble F, Beslot F, Dauge V, Fournie-Zaluski MC, Roques BP (2001). Delta9-tetrahydrocannabinol releases and facilitates the effects of endogenous enkephalins: reduction in morphine withdrawal syndrome without change in rewarding effect. Eur J Neurosci 13: 1816-1824.

Van Der Kooy D, Mucha RF, O'Shaughnessy M, Bucenieks P (1982). Reinforcing effects of brain microinjections of morphine revealed by conditioned place preference. Brain Res 243: $107-117$.

Vlachou S, Nomikos GG, Panagis G (2003). WIN 55,212-2 decreases the reinforcing actions of cocaine through CB1 cannabinoid receptor stimulation. Behav Brain Res 141: 215-222.

Welch SP, Eads M (1999). Synergistic interactions of endogenous opioids and cannabinoid systems. Brain Res 848: 183-190.

Wise RA, Leone P, Rivest R, Leeb K (1995). Elevations of nucleus accumbens dopamine and DOPAC levels during intravenous heroin self-administration. Synapse 21: 140-148.

Xi ZX, Stein EA (1999). Baclofen inhibits heroin self-administration behavior and mesolimbic dopamine release. J Pharmacol Exp Ther 290: 1369-1374.

Xi ZX, Stein EA (2000). Increased mesolimbic GABA concentration blocks heroin self-administration in the rat. J Pharmacol Exp Ther 294: 613-619.

Xi ZX, Stein EA (2002). GABAergic mechanisms of opiate reinforcement. Alcohol Alcohol 37: 485-494.

Yang CR, Mogenson GJ (1989). Ventral pallidal neuronal responses to dopamine receptor stimulation in the nucleus accumbens. Brain Res 489: 237-246. 